\title{
O QUE ANDAM A DIZER SOBRE EDUCAÇÃO, MUSEU E CIDADE EDUCADORA?
}

\section{WHAT IS THE LITERATURE SAYING ABOUT EDUCATION, MUSEUM AND EDUCATING CITY?}

\author{
Cristina Carvalho \\ Pontifícia Universidade Católica do Rio de Janeiro (PUC-Rio), Programa de Pós-Graduação em Educação; \\ $\mathrm{CTCH}$ - Centro de Teologia e Ciências Humanas, PUC-Rio \& Grupo de Pesquisa em Educação, Museu, Cultura \\ e Infância (GEPEMCI), PUC-Rio. Rua Marquês de São Vicente, 225, Edifíco Cardeal Leme, sala 1052, 22451-900 \\ Gávea, Rio de Janeiro, Brasil. Email: cristinacarvalho@puc-rio.br
}

João Teixeira Lopes

Universidade do Porto, Faculdade de Letras (FLUP), Departamento de Sociologia \& Associação Portuguesa de Sociologia. Via Panorâmica Edgar Cardoso, 4150-564 Porto, Portugal. Email: jlopes@letras.up.pt

\section{Clarisse Duarte Magalhães Cancela}

Universidade Federal do Estado do Rio de Janeiro (UNIRIO) \& Grupo de Pesquisa em Educação, Museu, Cultura e Infância (GEPEMCI). Rua Marquês de São Vicente, 225, Edifíco Cardeal Leme, sala 1052, 22451-900 Gávea, Rio de Janeiro, Brasil. Email: clahcancela@gmail.com

\begin{abstract}
Resumo: Este artigo pretende apresentar uma reflexão sobre a relação entre cidade educadora e museu, centrando-se no município de Taubaté e no Museu Monteiro Lobato, em São Paulo/Brasil. Em um primeiro momento, buscou-se conceituar esses termos para, então, efetuar uma busca por trabalhos que abordam a temática. Nessa revisão, foi possível constatar o reduzido número de estudos que tomam a relação "museu e cidade educadora" como objeto de investigação, apontando, assim, para a urgência de pesquisas nessa área.
\end{abstract}

Palavras-chave: cidade educadora, educação, Museu Monteiro Lobato, Taubaté.

\begin{abstract}
This article presents a discussion on the relationship between the educating city and the museum, focusing on the municipality of Taubaté and the Monteiro Lobato Museum, São Paulo/Brazil. Firstly, we conceptualized these terms as well as overviewed and discussed the scientific literature on this theme. In this review, we confirmed the small number of studies that take the relation "museum and educating city" as research object. As such, it is of the utmost importance to develop research in this area.
\end{abstract}

Keywords: educating city, education, Museu Monteiro Lobato, Taubaté.

\section{Introdução}

O ponto de partida para a produção deste artigo foi o interesse em investigar a relação entre cidade educadora e museu, tendo como recorte a cidade de Taubaté e o Museu Histórico, Folclórico Pedagógico, Monteiro Lobato (MHFPML), ${ }^{1}$ mais conhecido como Museu Monteiro Lobato, no Estado de São Paulo/Brasil. 
Julgamos necessário discorrer sobre o conceito de cidade e a sua influência na formação de identidade do cidadão, para então conceituarmos o de cidade educadora de modo a compreender o que essa expressão envolve e significa. Nesse sentido, consideramos igualmente importante apresentar a cidade de Taubaté para situar o leitor em relação ao espaço físico no qual esta pesquisa se situa.

O Museu Monteiro Lobato é importante referência na cidade de Taubaté, pois, como já denota no nome, se refere ao escritor brasileiro infantil mais conhecido no país. A função da instituição é manter viva a memória de Monteiro Lobato e, para tanto, exerce distintas atividades educativas dentro e fora do seu espaço.

O objetivo principal é tentar encontrar, na literatura, elementos que permitam dar conta de que Taubaté é uma cidade educadora, isto mediante a análise das ações educativas do museu em questão, mesmo entendendo que a cidade educadora não se restringe apenas à relação museu-cidade.

A escolha da metodologia utilizada nessa primeira etapa da pesquisa, a da revisão de literatura, pretendeu reunir alguns dos trabalhos produzidos sobre a temática, de modo a nortear os próximos passos da investigação. Verificamos que a produção, principalmente sobre cidade educadora, não é extensa, justificando a realização desta pesquisa.

Para orientar o tema da investigação, cabe destacar algumas questões que auxiliaram na análise de literatura: a) O que significa o museu para a população e para a cidade de Taubaté?; b) O museu se reconhece como instrumento para o desenvolvimento local?; c) $\mathrm{O}$ que Taubaté tem feito para inserir o patrimônio na vida de seus habitantes?; d) Como Taubaté influencia na construção da cidadania dos seus habitantes e, consequentemente, na formação cultural? Para complementar a investigação julgamos pertinente questionar também quem está autorizado a dizer que Taubaté não pode, mediante suas ações educativas, se configurar como cidade educadora? E, o que, de fato, caracteriza uma cidade como sendo cidade educadora?

\section{Situando o leitor: a cidade de Taubaté e o Museu Histórico, Folclórico e Pedagógico Monteiro Lobato (MHFPML)}

Taubaté, cidade situada no interior do Estado de São Paulo (Brasil), na região denominada Vale do Paraíba, possui em torno de 305 mil habitantes. ${ }^{2}$ A cidade aparece de modo pioneiro quando se fala de economia, mídia, educação, arte e cultura. Juntamente com outras cidades do mesmo Estado, é um dos municípios que apresenta ótima infraestrutura a nível cultural, com arquivos, bibliotecas, teatros, fundações, museus, etc. 
A cidade apresenta outras duas alcunhas mais conhecidas pela população: Capital Nacional da Literatura Infantil ${ }^{3}$ e Capital Universitária do Vale do Paraíba. A primeira decorre de um taubateano nacionalmente conhecido: o escritor Monteiro Lobato, também responsável pela obra literária Sítio do Pica Pau Amarelo. Ea segunda alcunha deve-se ao fato da cidade apresentar um dos melhores sistemas de educação da região, contando com um elevado número instituições de ensino nos diferentes níveis: educação infantil, fundamental, médio e quatro Universidades. ${ }^{4}$

O símbolo da cidade é o Museu Histórico, Folclórico e Pedagógico Monteiro Lobato (MHFPML), mais conhecido como Sítio do Pica Pau Amarelo. O espaço foi criado pelo Decreto Estadual n ${ }^{\circ} 33909$, de 04 de novembro de 1958, ${ }^{5}$ tendo sido aberto ao público apenas em 20 de abril de 1981, pois o imóvel precisou passar por diversas restaurações ${ }^{6}$ devido ao mau estado de conservação.

O processo de municipalização da instituição teve início em 2009, mas foi concluído em 2013. Desde então a Prefeitura de Taubaté é responsável pela sua gestão. Em relação a sua tipologia, o decreto de criação do museu o coloca como museu folclórico, mas também é possível denominá-lo de museu casa, histórico, pedagógico, de literatura, ${ }^{7}$ museu de cidade e da infância. ${ }^{8}$ Refletir sobre o que é este espaço e o que ele representa para a cidade é refletir igualmente sobre a importância e necessidade de um museu que possibilite a preservação da memória de grandes escritores brasileiros, não deixando, assim, que suas obras caiam no esquecimento.

O Sítio do Pica Pau Amarelo teve um Plano Museológico elaborado no ano de 2010 pela empresa Exposição, Museus e Projetos Culturais (Expomus) em parceria com a Associação Cultural de amigos do museu casa de Portinari (ACAM PORTINARI) e com a Secretaria de Estado da Cultura, através da Unidade de Preservação do Patrimônio Museológico do Estado de São Paulo (UPPM). A motivação para sua elaboração se deu ao entender que ao planejar sua gestão, o trabalho realizado pela instituição, seja ele de natureza operacional, administrativa, técnico, entre outros, se fortalece, promovendo assim a preservação e difusão do patrimônio cultural a curto, médio e longo prazo.

No Plano Museológico também é possível perceber a ênfase entre a relação do Museu com a cidade em que se localiza, onde a instituição é denominada de museu de cidade. Para Meneses (2003, p. 257): “o museu de cidade deve ser uma referência inestimável para conhecer a cidade, entendê-la (no seu passado e no presente), fruí-la, prever o seu futuro, enfim, amá-la e preocupar-se com ela e agir em consequência.". Ressalta-se também a importância do museu se inserir no espaço em que se encontra: 
Qualquer que seja seu tamanho, suas coleções e seu tipo de gestão, os museus devem desempenhar um papel capital no desenvolvimento da política de uma cidade. Não há desenvolvimento sustentável sem desenvolvimento cultural. Certamente, o museu está a serviço da sociedade. (Expomus, 2010, p. 4)

\section{A cidade e seu papel na formação cultural}

Para discorrer sobre o conceito de "cidade educadora" é necessário pensar o conceito de cidade e sua relação com a formação cultural dos citadinos. Rémy e Voyé a definem como:

(...) uma unidade social que, por convergência de produtos e de informações, desempenha um papel privilegiado nas trocas - materiais ou não - , em todas as actividades de direcção e de gestão e no processo de inovação. É por excelência, o lugar onde grupos vários, embora permanecendo distintos uns dos outros, encontram entre si possibilidades múltiplas de coexistência e de trocas mediante a partilha legítima de um mesmo território, o que não somente facilita os contatos programados, mas principalmente multiplica as hipóteses de encontros aleatórios e favorece o jogo das estimulações recíprocas. Lugar a partir do qual se estrutura o campo das atividades sociais, a cidade também confere uma dimensão sistemática à cultura regional circundante; pode também, pelo contrário, ser, em certos momentos, um lugar de ruptura e de inovação. (Rémy \& Voyé, 1992, pp. 14-15)

Na perspectiva dos autores, é possível compreender a cidade através de um conceito descritivo e um conceito interpretativo. $O$ descritivo se refere à realidade material como o espaço físico da cidade em si, sua arquitetura, seus espaços públicos e privados e a questão da densidade habitacional. Estes elementos morfológicos distintos permitem perceber que a cidade apresenta diversas funções e que estas estão inter-relacionadas com seus espaços. Já o conceito interpretativo passa pela questão da definição da relação entre a apropriação do espaço e a dinâmica coletiva que se estabelece. É possível distinguir dois tipos de apropriação: para um determinado grupo social, o espaço pode ser um trunfo e/ou impulsionador da mobilidade; para outro, o mesmo espaço pode se constituir como uma desvantagem que limita e/ou exclui este grupo da mobilidade, ou seja, exclui efetivamente alguns grupos da participação do meio urbano.

Mover-se pelo espaço muitas vezes demanda certo aporte econômico, porém, mais do que isso, se a possibilidade cultural adquirida for reduzida, desenvolve-se a necessidade de um enraizamento espacial concreto, limitando a mobilidade, pois as referências concretas não são transponíveis a outros espaços. Percebe-se esta 
condição nos grupos sociais menos favorecidos, implicando nas suas condições de relações sociais, pois estas ficam mais restritas às condições de anonimato ou limitadas à vizinhança. No entanto, quando a capacidade cultural é ampliada, a necessidade de pontos de referência concretos é limitada, aumentando a capacidade de mobilidade, pois a proximidade espacial não é determinante para a construção das relações e as barreiras físicas tornam-se mais facilmente transponíveis pela capacidade de abstração que, por conseguinte, permite maior domínio dos espaços não antes conhecidos. Percebe-se esta condição nos grupos sociais mais favorecidos, implicando também nas suas condições de relações sociais que acabam por se desenvolver.

Segundo Canclini (2013), o espaço público ainda apresenta ruptura entre os bairros de zonas mais ou menos qualificadas e se torna mais complexo mediante três fatores: o alargamento dos meios virtuais de comunicação, a convivência e a segregação, complexificando também a questão da mobilidade. O autor afirma que:

As cidades, sobretudo as grandes cidades, são sistemas espaciais e redes de comunicação. Uma cidade habita-se e faz-se circular, e ambos os modos de a ocupar complementam-se: movimentar-se para trabalhar e consumir é, supostamente, uma maneira de a usar. Portanto, a cidade forma seus habitantes pelos procedimentos em que organiza a ocupação do espaço e pelas oportunidades que oferece de informar-se, conhecer e actuar comunicando-se. (Canclini, 2013, p. 157)

Rémy e Voyé (1992), referindo-se às trocas, e Canclini (2013), ao mencionar o uso da cidade, fazem alusão à mobilidade, pois é ela que facilita ou dificulta o uso dos espaços, e é nesse mesmo espaço urbano que a sociedade se expressa, sendo possível dizer que as relações espaciais são relações sociais.

O processo de urbanização é modificado pela relação entre a vida social e o local em que se habita, já que havia uma necessidade de morar perto do local de trabalho antes da urbanização e, hoje em dia, já não é algo tão necessário devido à facilidade de locomoção.

Como já mencionado, o ponto central de uma cidade é a mobilidade e, visto que ela agiliza as trocas - materiais ou não - , tem também influência na questão da formação cultural, compreendendo-a como troca de conhecimento. A este respeito Bauman (2013) faz uma reflexão sobre a sociedade em que vivemos: a do conhecimento ou da informação? Apesar de existir número maior de informações produzidas e disponibilizadas, nem todas são entregues, havendo ainda retenção por parte de um grupo mais favorecido. O autor aponta então para uma sociedade da informação, e, ainda que a cidade contribua para uma formação cultural, nem todos os grupos são beneficiados, acentuando as desigualdades sociais. 
Para Canclini (2013), a contribuição da cidade para o desenvolvimento cultural se dá quando há uma combinação entre as comunicações tecnológicas e o conhecimento histórico-territorial, o que vai ao encontro do pensamento de Rémy e Voyé: "a proximidade territorial já não é a base prioritária da proximidade cultural e as formas culturais autonomizam-se em relação ao enraizamento regional de tal modo que o papel do espaço se vai reduzindo no fechamento das redes de interdependência" (Rémy \& Voyé, 1992, p. 87).

Lopes (2008) também entende que a mobilidade real é ingrediente necessário para uma melhor formação cultural, já que transitar pela cidade amplia o capital econômico, cultural e social, facilidade que, em geral, está ligada às classes sociais mais altas. No entanto, para as classes menos favorecidas geralmente se oferece uma mobilidade virtual que não quer dizer uma inclusão real, pois ter acesso à tecnologia não significa saber usá-la, mascarando assim uma suposta mobilidade real.

Ainda sobre a questão dos grupos menos favorecidos, Moll (2013, p. 215) destaca que "para estes, grupos ou indivíduos ["sem casa, sem família, sem escola"], perdidos e isolados no fluxo das cidades, ao contrário, a rua - via - de - regra - representa insegurança, violência e guetização", aspecto que afasta cada vez mais da necessária mobilidade real e de uma formação cultural. A autora também questiona: como se tornar habitante da cidade, visto que para muitos cidadãos não é facilitada a exploração do espaço urbano?

É importante entender que a cidade tem grande influência na identidade social do cidadão, ressaltando-se a mobilidade que se tem pela cidade, pois o uso do espaço público é condição do cidadão e é através da sua exploração que a formação cultural é fortalecida e, consequentemente, sua identidade social, é formada.

Quando mencionamos identidade social, cidadania e uso do espaço é possível pensar sobre cidade educadora, já que seu propósito é valorizar a função educativa da cidade, entendendo que esta mesma educação não deveria ficar restrita a certos espaços e enquanto privilégio para alguns grupos. A educação, em sentido amplo, é primordial para que se compreenda um uso mais adequado da cidade, e consequentemente, do "ser cidadão".

O conceito de cidade educadora, antes conhecido como Cidade Educativa, foi elaborado pela Organização das Nações Unidas para a Educação, a Ciência e a Cultura (UNESCO) na década de 1970. Em 2004 foi redigida a proposta definitiva da Carta das Cidades Educadoras contendo seus propósitos e objetivos, bem como a definição do que seria uma cidade educadora:

A cidade educadora tem personalidade própria, integrada no país onde se situa é, por consequência, interdependente do território do qual faz parte. É igualmente uma cidade que se relaciona com o seu meio envolvente, outros centros urbanos do seu 
território e cidades de outros países. O seu objectivo permanente será o de aprender, trocar, partilhar e, por consequência, enriquecer a vida dos seus habitantes. (Carta das Cidades Educadoras, 2004, p. 2)

Vieira e Aquino (2015) afirmam que a definição de cidade educadora, por ser ampla, é aplicável a outros espaços/cidades que não configuram na lista da Associação Internacional das Cidades Educadoras (IAEC), ${ }^{9}$ desde que esses mesmos espaços se perguntem sobre seus objetivos e que tipo de homens querem formar. Os autores definem a missão e objetivo de uma cidade educadora:

(...) promoção de cidadania, lazer, esporte, saúde, cultura, etc. (...). Como objetivos específicos, destacam-se o desenvolvimento da consciência ambiental, a melhoria da qualidade de vida, o aumento da participação política e o fortalecimento da memória e da identidade cultural via vinculação com o patrimônio urbano. (Vieira \& Aquino, 2015, p. 319)

Conforme já destacado anteriormente, a cidade tem um potencial educativo e influencia na identidade dos seus habitantes, porém, essa mesma cidade será mais educadora à medida que houver maior diálogo entre ela e as instituições que a compõem para que haja uma melhor coordenação das políticas educativas. Nesta perspectiva, será possível desenvolver o potencial educativo de cada espaço e, consequentemente, ampliar a formação cultural, além de combater a exclusão, tanto física quanto social, através de uma reestruturação da mobilidade.

Ao abordar o conceito de educação para a cidade educadora, englobamos a educação formal, não formal e informal sem hierarquizá-las, pois defendemos o diálogo e a participação dos cidadãos para que se apropriem e se identifiquem cada vez mais com o território em que estão inseridos.

Em suma, uma cidade educadora com identidades fortes é aquela que, entre muitas outras dimensões, assenta numa sociedade civil que respeita todas as vidas, recusa a violência, promove a generosidade e a solidariedade, combate as formas de exclusão e injustiças, defende a liberdade e a diversidade cultural, preserva o ambiente e o patrimônio, reinventa o espaço público convivial, preserva a memória e se projeta em ambientes de inovação criativa, de (re)construção de identidades. (Guarda, 2017, p. 5)

\section{O museu e a cidade}

Para que a cidade seja uma cidade educadora é necessário cumprir alguns requisitos: sua adesão ser aprovada por órgão municipal da cidade; cumprir os princípios da Carta das Cidades Educadoras; participar dos canais de debate da Associação 
Internacional das Cidades Educadoras e pagar a cota anual. No entanto, nada é colocado por este mesmo órgão quando se pensa em ações fiscalizadoras para verificar se a cidade está de fato, sendo educadora.

A Carta das Cidades Educadoras (2004) destaca três princípios: "o direito a uma cidade educadora", "o compromisso da cidade" e "ao serviço integral das pessoas". A cidade que quiser se tornar uma cidade educadora deve seguir estas diretrizes, pois:

A cidade educadora deve exercer e desenvolver esta função paralelamente às suas funções tradicionais (económica, social, política de prestação de serviços), tendo em vista a formação, promoção e o desenvolvimento de todos os seus habitantes. Deve ocupar-se prioritariamente com as crianças e jovens, mas com a vontade decidida de incorporar pessoas de todas as idades, numa formação ao longo da vida. (Carta das Cidades Educadoras, 2004, p. 2)

Ao ter como objetivo o desenvolvimento de seus habitantes, a cidade deve investir em equipamentos culturais, acolhendo distintas manifestações culturais, sejam elas inovadoras ou da cultura popular. O município deve ofertar debates, espaços de formação e intercâmbio cultural para que auxilie o munícipe a construir sua identidade cultural e, consequentemente torná-lo cidadão. Certamente "cidadania" é um conceito amplo, mas, de modo geral, no contexto deste artigo, nos referimos à capacidade de a população ter meios para discernir, pensar e opinar sobre aspectos que permeiam nosso cotidiano, exercendo seu papel de cidadão.

Entendemos que não é só o museu que tem a capacidade de fazer com que a cidade se torne uma cidade educadora. É necessário que toda a cidade se envolva neste projeto, no entanto, entendemos também que o Museu Monteiro Lobato apresenta uma capacidade de articulação entre governo e população que acaba por se destacar num possível processo de pensar Taubaté como cidade educadora.

Além das atividades que promovem dentro do espaço físico do museu - teatro, contação de histórias, visitas guiadas - há duas (2) atividades que o Sítio do Pica Pau Amarelo promove com a intenção de aproximá-lo do seu território e contribuir para o significado de "cidade educadora" aqui atribuído a Taubaté: Trilha Cultural e Passeio do Visconde. A primeira, teve início em 2014 e tem o objetivo de incentivar a população a visitar os museus da cidade:

A ação contemplou nove museus locais, com o objetivo de especializar suas estratégias de comunicação institucional e formatar de um Plano de Comunicação Institucional em Rede. Foram confeccionados trinta mil folders para distribuição gratuita, que apresentam instituições de Taubaté enquanto excelentes oportunidades de cultura, 
lazer e diversão. O estudo tem como proposta identificar e valorizar a diversidade do patrimônio natural, histórico e cultural, resguardado nos equipamentos da região. ${ }^{10}$

Para atingir este objetivo, o Sítio e outros museus vão até as escolas, fazem oficinas e depois convidam o público para irem até os museus. O Passeio do Visconde, que também se iniciou em 2014 é um projeto de educação patrimonial que tem como objetivo "levar a comunidade a um processo ativo de reconhecimento crítico, apropriação consciente e valorização de sua herança cultural através da visitação monitorada aos patrimônios culturais taubateanos" ${ }^{11}$

A perspectiva defendida neste artigo é de que quanto mais diálogo houver entre o museu e a comunidade, maior a possibilidade da comunidade se sentir detentora do patrimônio que a cerca, intensificando sentimentos de cidadania e identidade, além do reconhecimento da importância de se preservar o patrimônio que está dentro dos museus. Quando os museus realizam ações fora do seu espaço físico, seja em um bairro, ou em uma praça, por exemplo, aproximando-se cada vez mais de seu território, estão desconstruindo a ideia de que somente "escolarização [é] decisória da condição de cidadão" (Arroyo, 2010, p. 23).

A diversidade é inerente às cidades actuais e prevê-se que aumentará ainda mais no futuro. Por esta razão, um dos desafios da cidade educadora é o de promover o equilíbrio e a harmonia entre identidade e diversidade, salvaguardando os contributos das comunidades que a integram e o direito de todos aqueles que a habitam, sentindo-se reconhecidos a partir da sua identidade cultural. (Carta das Cidades Educadoras, 2004, p. 3)

\section{Alguns estudos sobre museus, educação e cidade educadora}

\section{Breve relato sobre os museus}

Em 2009, no Brasil, o Estatuto de Museus ${ }^{12}$ apresentou, em seu primeiro artigo, uma definição para essas instituições:

Consideram-se museus, para os efeitos desta Lei, as instituições sem fins lucrativos que conservam, investigam, comunicam, interpretam e expõem, para fins de preservação, estudo, pesquisa, educação, contemplação e turismo, conjuntos e coleções de valor histórico, artístico, científico, técnico ou de qualquer outra natureza cultural, abertas ao público, a serviço da sociedade e de seu desenvolvimento. (Lei n. ${ }^{\circ} 11904 / 09,2009$, p. 1)

Nessa definição se enquadram também as "instituições e os processos museológicos voltados para o trabalho com o patrimônio cultural e o território visando ao 
desenvolvimento cultural e socioeconômico e à participação das comunidades." (Lei n. ${ }^{\circ} 11904 / 09,2009$, p. 1). Foram igualmente definidos princípios fundamentais dos museus em seu artigo segundo:

I - a valorização da dignidade humana; II - a promoção da cidadania; III - o cumprimento da função social; IV - a valorização e preservação do patrimônio cultural e ambiental; V - a universalidade do acesso, o respeito e a valorização à diversidade cultural; VI - o intercâmbio institucional. (Lei n. ${ }^{\circ}$ 11904/09, 2009, p. 1)

Em uma breve análise, é possível distinguir dois momentos distintos na narrativa dos museus: num primeiro período, esse espaço não era aberto ao público em geral e sim à elite econômica e erudita, assumindo como função principal o ensino e a pesquisa voltados apenas aos pares. Num segundo momento, no século XVIII, os museus foram paulatinamente abertos ao público, provocando então a necessidade de se reinventar. A informação entre pares, que circula apenas no âmbito dos museus, seria agora finalmente voltada também para o público leigo, externo à área científica. Como fazer tal adaptação? As coleções assumiram papel de destaque nesse movimento, contribuindo para a difusão da informação que se pretendia "passar" a esse novo público.

Pode-se dizer que os museus são a forma "mais clássica" da "educação não formal" na sociedade. Este rótulo data do século XX e, segundo Trilla et al. (2008), as modificações ocorrem no âmbito das estruturas e metodologias, pois a educação não formal abrange outros tipos de espaços, procedimentos, agentes, entre outros. Buscando uma definição, o autor compreende que educação não formal é "o conjunto de processos, meios e instituições específica e diferenciadamente concebidos em função de objetivos explícitos de formação ou instrução não diretamente voltados à outorga dos graus próprios do sistema institucional regrado" (Trilla et al., 2008, p. 42).

Como é possível perceber, a questão educacional está intrínseca aos museus, que, apesar de não ter a obrigação de educar, possuem o potencial e a intenção de fazê-lo. Sander destaca a importância de se pensar essa relação educativa:

Ao pensar a relação educativa do museu fundamentada na perspectiva emancipatória proposta por Paulo Freire, os educadores e agentes responsáveis pela socialização do patrimônio cultural podem refletir sobre a importância dos espaços educativos não formais na formação da subjetividade das pessoas, desencadeando um processo reflexivo sobre a utilização dos espaços museológicos na prática pedagógica e permitindo redirecionar a ação pedagógica numa perspectiva crítica, que valorize a diversidade cultural e as memórias das comunidades. (Sander, 2006, p. 14) 
Com o intuito de ampliar a reflexão sobre a relação entre "educação" e "museus", apresentamos a investigação de Seibel-Machado (2009), um extenso e minucioso trabalho sobre esta temática com um recorte temporal de 1987 e 2006. O estudo de Vianna (2015) apresenta o levantamento até 2014 em todo o Brasil, ampliando assim a pesquisa realizada por Seibel-Machado (2009).

A investigação de Seibel-Machado (2009) teve como objetivo destacar o papel do setor educativo dos museus, assinalando suas abordagens pedagógicas a partir da literatura produzida nos estados de São Paulo e Rio de Janeiro. Ao analisar os trabalhos, apresenta as instituições estudadas, os temas, objetivos, formação dos autores, referenciais teóricos e metodologia, bem como aponta lacunas e contribuições. Nesta análise destaca o quanto o museu não é neutro, nem suas ações, tendo como pressuposto que a prática educativa é intencional e atende determinados públicos. Formula então novas reflexões e questões para tentar produzir uma prática educativa que seja transformadora, respaldada também em sua experiência no setor educativo do Museu da Vida, localizado na cidade do Rio de Janeiro.

Além de ser uma prática intencional, a literatura trata a educação como um dos principais objetivos dos museus de distintas tipologias e avalia que o setor educativo é responsável por desenvolver as ações educativas. No entanto, de modo geral, os estudos não esclarecem que tipo de educação é esta e como desenvolvê-la, o que pode ocasionar a "escolarização do museu" já que, por vezes, toma-se como referência as diretrizes voltadas para as práticas escolares. Corre-se então o risco de se voltar à questão do museu como complemento escolar, o que seria uma redução do que de fato o museu ée pode ser. Para a autora falta, portanto, informação e orientação nas ações desenvolvidas pelos profissionais e considera que:

[como] os museus estão inseridos numa sociedade cindida por profundas desigualdades econômico/sociais, políticas e culturais, a identificação e explicitação dos referenciais que informam a sua prática educativa nos ajudam a compreender os interesses que eles priorizam nas ações educativas que oferecem ao público visitante. (Seibel-Machado, 2009, p. 4)

No entanto, da mesma maneira que os museus podem ser reprodutores de discursos, podem também, segundo Seibel-Machado:

(...) contribuir para a sua transformação, ao buscar possibilidades de construir, no âmbito das contradições e dos limites do sistema capitalista, propostas e situações educativas que favoreçam a construção de relações sociais voltadas para um outro tipo de sociedade. É nessa perspectiva teórica que buscaremos entender a questão educativa nos museus. (Seibel-Machado, 2009, pp. 11-12) 
Na literatura analisada, a autora identificou que a temática mais frequente era de avaliação dos processos educativos e de denúncia à má condição de trabalho nos setores educativos, o que é contraditório, visto que para o museu a educação é importante. Seibel-Machado (2009) constatou também que a maior parte dos princípios pedagógicos que norteiam as ações educativas são aqueles que estão presentes no ensino formal em distintos momentos, como escolanovismo, tecnicismo, entre outros.

Vianna (2015) trabalha com o enfoque na educação de jovens e adultos (EJA) e da sua relação com os museus. Buscando delinear as pesquisas sobre a temática, realizou também um levantamento bibliográfico sobre a educação nos museus no período de 2007 a 2014, utilizando como fontes o Banco de Teses da CAPES e da Biblioteca Digital Brasileira de Teses e Dissertações (BDTD). Tendo em vista o enfoque na EJA, que não se configura como objeto da reflexão aqui apresentada, destaca-se apenas que, no seu levantamento, a autora percebeu que os museus de ciência, por sua relação histórica com a educação, são o foco principal dos pesquisadores que estudam esta temática. Além disso, ressaltou que as produções voltadas para a relação EJA e museus são poucas, apresentando lacunas que merecem ser compreendidas:

A importância de se perceber como se dá a ressignificação dos espaços museais por parte dos professores tem a ver com as especificidades dos estudantes jovens e adultos das escolas públicas e o necessário movimento de (re)apropriação de contextos e de diferentes práticas culturais que ocorrem e se (re)inventam em outros espaços que educam na sociedade, para além da escola, por toda a cidade. (Vianna, 2015, p. 54)

\section{Entrelaçando as palavras-chave}

A pesquisa teve por base as seguintes palavras-chave: "cidade educadora", "educação patrimonial" e "Museu Monteiro Lobato". Uma busca foi realizada a partir das fontes: Banco de Teses e Dissertações da Capes; Google acadêmico; e base SciELO (Scientific Electronic Library Online), compreendendo o recorte temporal de 2012 a 2016.

Tendo por base o Banco de Teses e Dissertações da Capes, ao buscar por "Museu e cidade educadora" ou "educação patrimonial e museu" nenhum resultado foi obtido. Na mesma plataforma, a ausência de trabalho se repetiu ao entrar com "cidade educadora e museu". Entretanto, ao realizar a pesquisa apenas com "cidade educadora" o retorno foi de cinquenta e dois (52) resultados. Desse total, vinte e três (23) estão dentro do recorte temporal e, analisando os trabalhos, considera-se que três (3) se relacionam com a pesquisa a ser desenvolvida. 
O primeiro trabalho que se relaciona com a pesquisa é de Martin (2014) que teve como objetivo geral avaliar as ações dos municípios paulistas que, no ano de 2012, estavam associados ao Movimento das Cidades Educadoras. Dentre seus objetivos específicos, destaca-se: investigar o Movimento das Cidades Educadoras levando em conta seu contexto histórico, elementos e pressupostos que o compõe. Para o desenvolvimento da pesquisa, recorreu à abordagem quali/quantitativa, análise documental e pesquisa bibliográfica. O conceito de cidade educadora e sua trajetória histórico-temporal configuram-se como aspectos explorados por Martin (2014), utilizando referências como a da Carta das Cidades Educadoras.

Temas como educação formal, não formal e informal são igualmente contemplados pela autora, pois acredita que a cidade educadora tem o potencial de educar ao longo da vida, assim como os museus e as escolas. Tanto a cidade educadora quanto os museus praticam a educação não formal, já a escola, a educação formal, e os três espaços podem ser vistos como "espaços de aprendizagem e de socialização" (M. C. Carvalho, 2016, p. 78). Martin (2014) também pontua dois aspectos importantes sobre a cidade educadora que estão interligados: o primeiro refere-se à natureza das políticas que norteiam as ações, vinculadas ao Estado e não ao governo, ponto que merece atenção para que as metas estabelecidas sejam mantidas quando houver troca de governo. O segundo aspecto faz alusão a não existência de um modelo de cidade educadora, já que seu conceito é dependente da dinâmica de cada cidade e o sucesso de suas ações está relacionado a sua gestão/política. Ambos os pontos destacados são importantes para pensarmos o que é uma cidade educadora, sua concepção e seus objetivos.

Em suas conclusões, a autora ressalta o quanto os princípios básicos da cidade educadora estão embasados na democracia, onde há diálogo entre instituições, habitantes e governo local. Quanto mais diálogo houver entre estas instâncias maior a possibilidade da população se sentir detentora do seu patrimônio, entendido aqui como a cidade e tudo o que nela está contemplado, intensificando sentimentos de cidadania e identidade. Nesta perspectiva, à medida que nos apropriamos cada vez mais do território ao qual estamos inseridos, menos a escola se torna lugar único de construção de cidadania.

É importante ressaltar que o que norteia as ações das cidades educadoras são as peculiaridades de suas histórias, culturas, necessidades dos diferentes grupos existentes na sociedade, entre outros fatores. Cabe também lembrar que não se pode pensar em apenas uma identidade, pois a cidade é o espaço onde constantemente recriamos nossa identidade.

Após a análise apresentada por Martin (2014) e uma reflexão sobre a cidade a ser pesquisada - Taubaté - , é possível destacar que, apesar de não estar inserida 
na Associação Internacional das Cidades Educadoras (IAEC), muitas ações do governo municipal podem ser classificadas como princípio das cidades educadoras, visto que prezam a participação popular. Além disso, a cidade já ostentou o título de "Cidade educacional por excelência". ${ }^{13}$ Segundo Vieira e Aquino (2015, p. 317) "a concepção de cidade educadora acabou por se tornar um princípio expandido e aplicável a âmbitos mais amplos e diversificados".

Retomando a busca por trabalhos desenvolvidos sobre a temática em questão, a pesquisa realizada por Gomes (2013) teve como propósito observar a dinâmica da educação e o protagonismo que a cidade vem ganhando no papel educador ao analisar o Programa Bairro Escola do município de Nova Iguaçu, localizado no estado do Rio de Janeiro. O autor pontua a importância da educação "fora dos muros da escola" e a urgência de construção de um diálogo entre cidade e educação. Destaca, ainda, que a cidade permite diferentes práticas educacionais, sejam elas da educação formal, informal ou não formal, e a formação de novas políticas voltadas para a educação.

Para orientar sua pesquisa, e com a intenção de tornar a cidade um cenário de análise, o autor apresenta alguns questionamentos: "Como a cidade atua enquanto lócus de realização e geração de práticas educacionais? (Cidade "palco" ou cidade "ativa" ?); Qual é a natureza das práticas educacionais geradas e realizadas na cidade?; A cidade educa (por si só)?" (Gomes, 2013, p. 17). Ressalta, como maior desafio, a mudança de locus do seu olhar, pois, ao se analisar a educação pelo viés escolar é possível identificar práticas já demarcadas, bem como sujeitos delimitados (estudantes), mas, ao se debruçar para aspectos que envolvem a cidade, que instrumento pode orientar o olhar? Quem são os sujeitos? Quais são as práticas? Qual o papel das instituições que a compõe?

Para discutir a questão da cidade e educação, Gomes (2013) apresenta conceitos de educação formal, não formal e informal, onde praças, museus, bibliotecas, entre outros, seriam utilizados como espaços educativos em uma concepção ampla da educação que, nos dias atuais, não pode mais ser associada apenas à escola. O autor conclui, portanto, que a cidade não é agente já que seu papel educacional é inconsciente; no entanto, compreende que a cidade inspira e traz uma outra dimensão aos processos educacionais, tornando fundamental o diálogo. Para complementar a ideia ampliada de educação, recorremos a Dourado e Oliveira que consideram que: "a educação deve ser entendida como espaço múltiplo, que compreende diferentes atores, espaços e dinâmicas formativas (...). Nessa direção, a educação é entendida como elemento constitutivo e constituinte das relações sociais mais amplas." (Dourado e Oliveira, 2009, p. 203).

O último trabalho de busca com o conceito "cidade educadora" é o de M. P. Carvalho (2014). A autora aborda, além do conceito de cidade educadora, o de 
Educação Patrimonial, dialogando com diversos autores. Buscou, dentre outras questões, as potencialidades da Educação Patrimonial junto aos professores da rede municipal de ensino da cidade de Vila Velha, localizada no Estado do Espírito Santo (Brasil). Sua perspectiva é no sentido de estimular a cidade como espaço formativo que tem o objetivo de construir a cidadania e conscientizar a população em relação ao patrimônio local. Ao longo do trabalho é descrita a relação entre cidade e educação, apresentando as práticas educativas que o meio urbano possibilita, como, por exemplo, museus, a própria escola, biblioteca etc.

É possível pensar que o conceito de cidade educadora e de educação patrimonial estejam atrelados, pois ambos entendem o diálogo como importante ferramenta para explorar o meio urbano, conhecer e dar significados ao patrimônio e, consequentemente, aprender a respeitá-lo. Segundo a autora "o espaço da cidade possui ampliadas possibilidades de práticas educativas, configura-se como um local de ações sociais, políticas, culturais, vivências que nos colocam em contato com diferentes formas de agir, pensar e sentir" (M. P. Carvalho, 2014, p. 49).

Ainda no trabalho de busca na base do Banco de Teses e Dissertações da Capes ao unir no recorte temporal proposto - "museu" "educação patrimonial" e "cidade educadora" - obteve-se mil oitocentos e doze (1812) resultados. Optou-se então por também refinar a busca nas áreas de concentração "Educação" e "Museologia e Patrimônio", e o resultado foi de cento e quarenta e nove (149) estudos; porém, após uma análise dos trabalhos, foi possível constatar que apenas três (3) se relacionavam com a pesquisa a ser desenvolvida.

Destes, o primeiro trabalho é de A. D. H. Silva (2013), que analisa a questão da educação em museus através do Comitê de Educação e Ação Cultural (CECA), vinculado ao International Council of Museums (ICOM). Assim como Seibel-Machado (2009), o estudo busca identificar os pressupostos teóricos que guiam as práticas educativas nos museus. É interessante notar que, em um intervalo de seis anos, esta questão ainda é recorrente, ou seja, será que, mesmo a educação sendo primordial no museu, ainda assim, não é interessante refletir sobre seu papel na sociedade bem como modificar suas ações educativas de modo que tenha um maior alcance para todas as classes sociais e não seja um mero reprodutor de práticas escolares?

A autora ressalta que a intenção de relacionar o homem, a educação, a função social e a cultura aparece no documento do CECA, propondo um museu que trabalhe na perspectiva de educar para transformar e trazer o público excluído para dentro da instituição, pois ainda há um público em potencial fora dos museus, já que, na maioria das vezes, existe um segmento da população que não se sente inserido no espaço cultural, geralmente em decorrência das diferenças sociais. Ou seja, quem é então o real visitante que vai ao museu? 
O outro trabalho identificado nessa revisão de literatura é o de C. F. Silva (2013) que apresenta um estudo de caso sobre os exemplares dos periódicos Núcleo de Orientação e Pesquisa Histórica (NOPH) - 1984 a 1990 - e o Quarteirão, que se originou do próprio NOPH - 1993 a 2000 - , buscando compreender como se deu as representações sobre patrimônio, museu comunitário, ecomuseu e museu (C. F. Silva, 2013). O periódico NOPH surgiu com a intenção de divulgar as ações do Núcleo de Orientação e Pesquisa Histórica de Santa Cruz e do ecomuseu, criado em 1993, no bairro de Santa Cruz, no Rio de Janeiro. Para discorrer sobre ecomuseu, a autora dialoga com autores que buscaram construir esse conceito:

Eu vou do mais simples, pois não há um modelo e, ao contrário, há uma grande diversidade de aplicação do conceito. Eu prefiro dizer: o museu "normal" é um prédio, uma coleção, o público/ O ecomuseu é um território, o patrimônio, uma comunidade. O museu normal é a cultura "acima do sol". O ecomuseu é um museu enraizado na cultura viva dos habitantes. É necessário também definir os objetivos. Para mim, o ecomuseu faz parte do instrumento da dimensão cultural do desenvolvimento local. Os museus comuns, ao invés disso, tem preferido com objetivos o desenvolvimento da cultura, a conservação do patrimônio, o acolhimento dos turistas, a formação das escolas etc. ${ }^{14}$ (Varine, 2006, p. 5) (tradução nossa)

C. F. Silva (2013) também ressalta o quão importante foi o Ecomuseu de Santa Cruz no sentido de valorizar o bairro em que se insere e seu patrimônio, destacando igualmente a relevância dos periódicos avaliados - NOPH e o Quarteirão - para um processo de autorreconhecimento por parte da comunidade.

Retomando os espaços que serão objetos da investigação a ser desenvolvida - a cidade de Taubaté e o Museu Histórico, Folclórico e Pedagógico Monteiro Lobato - , além de refletir sobre a categoria de cidade educadora, é possível também pensar sobre um outro aspecto que envolve este espaço museológico: será que esta instituição pode se configurar como um ecomuseu, já que, segundo Varine (2006), se constitui em patrimônio, território e comunidade, aproximando-se do objetivo da cidade educadora, que também pensa na questão do território e do desenvolvimento da vida dos seus cidadãos?

Por último o trabalho de Melo (2015), que investigou questões sobre a educação museal e sua relação com elementos que constituem a escola. Ao optar por utilizar o termo "educação museal", a autora apresenta um levantamento bibliográfico relevante e o confronta com "educação patrimonial", dialogando com Chagas (2009) e Cabral (2012) na tentativa de conceituar esses termos. Num primeiro momento os dois conceitos são percebidos como sinônimos, porém, a autora afirma, a posteriori, que a "educação patrimonial" estaria ligada à 
preservação do patrimônio e a "educação museal" seria utilizada como a ação educativa que se dá no museu.

Em seu trabalho, Melo (2015) segue abordando o cenário da educação museal e o quão escasso configura-se pesquisas que se utilizam desta expressão, já que ainda é um conceito recente e se aproxima do conceito de Educação Permanente criado pela UNESCO em 1960, que reforçava a ideia de complemento à educação formal. No entanto, muito mais do que o nome dado ao conjunto de ações educativas praticadas nos museus - "educação museal", "educação em museus" e outros, o que de fato o aproxima da educação formal e o torna complementar é a maneira como são realizadas suas práticas educativas. Ressalta-se também que a abordagem não recai sobre a escola, representante clássico da educação formal, como algo negativo, mas os museus não apresentam os mesmos objetivos, logo, é urgente pensar em práticas educativas diferenciadas.

No Google acadêmico foi também utilizado o mesmo recorte temporal (2012-2016). Ao buscar - "Museu Monteiro Lobato e cidade educadora" - , obteve-se zero (0) resultados. Entretanto, na busca por "Museu Monteiro Lobato", foram localizados quatro (4) trabalhos, sendo que um (1) se relaciona com a temática da investigação.

O trabalho é o de Rodriguez (2015) que abordou residências particulares que se tornaram museus e cita o Museu Monteiro Lobato, pois este foi moradia do avô de Monteiro Lobato, José Francisco Monteiro (Visconde de Tremembé). Sobre o nascimento do neto não se sabe ao certo se foi na mesma Chácara ou em outro local, mas ele visitava seu avô constantemente. O Museu Histórico, Folclórico, Pedagógico Monteiro Lobato está cadastrado como histórico, pedagógico, folclórico e de literatura, ${ }^{15}$ mas também pode ser pensado como museu-casa e até ecomuseu, pois tem como objetivo aproximar a personagem principal da sociedade em que se localiza, bem como divulgar a obra do escritor.

Nesse sentido, de acordo com Plano Museológico “O Museu Histórico, Folclórico e Pedagógico Monteiro Lobato tem como missão a preservação e a divulgação da obra de Monteiro Lobato, por meio de programas de preservação, comunicação e pesquisa, voltados para diferentes segmentos da sociedade" (Expomus, 2010, p. 25).

Analisando então a missão expressa pelo Museu, é possível encontrar algumas especificidades das casas museu apontadas por Rodriguez (2015), como: vontade e necessidade de preservar a memória em questão e a existência de acervo material e imaterial que torne viva a lembrança do personagem. Além disso, nesta tipologia de museus, acervo e proprietário estão profundamente vinculados, como constatado no museu em questão. 
Na mesma plataforma de busca, o Google acadêmico, ao entrar com "cidade educadora e museu", nenhum resultado foi obtido, mas, com a procura por "cidade educadora" foram localizados oitocentos e setenta e nove (879) resultados. Ao refinar a busca, unindo "museu" "educação patrimonial" "cidade educadora", foram gerados trinta e seis (36) resultados, dos quais dois (2) são pertinentes para a presente pesquisa.

É de destacar o trabalho de Cury e Moraes (2012), que procurou investigar o conceito de Educação Patrimonial em relação à valorização do patrimônio e à crescente oportunidade de diálogo com o campo da educação. Os autores compreendem que a noção de patrimônio se expandiu, sendo necessário entender as diferentes manifestações culturais relacionadas à dinâmica das cidades. Explicitam então a importância do acesso a esse patrimônio e citam como exemplo os programas educativos Ciudad Educadora e La cittá dei Bambini, que incentivam os habitantes a se engajarem nas questões relacionadas à vida social da cidade para compreenderem o universo da cultura e perceberem que os campos da Educação e do Patrimônio influenciam as políticas culturais da cidade.

Franco, Prados e Bonini (2015) investigaram a formação da cidadania dos alunos da educação básica da cidade de Guararema, também localizada no Estado de São Paulo, através do potencial educativo do patrimônio material e imaterial. A intenção dos autores foi refletir sobre a Educação Patrimonial na cidade educadora e problematizar a prática educativa, seja ela formal ou não formal, que apenas transmita e contemple o patrimônio sem dar a ele qualquer sentido, no intuito de colaborar para uma gestão do patrimônio cultural. Nesta perspectiva, a Educação Patrimonial assume papel importante enquanto possibilidade de um diálogo entre os educandos e cidadãos e sua postura em relação aos bens culturais. Os autores reforçam que para uma melhor apropriação crítica do patrimônio é necessário que se ultrapasse o espaço escolar, envolvendo diversas instituições, pois compreendem que deste modo o sentimento de responsabilidade com o patrimônio cultural se torna maior, já que igualmente reforça o sentimento de pertença.

Por fim, na base SciELO não foi localizado nenhum resultado com os conceitos propostos.

\section{Considerações finais}

Apesar da vasta literatura sobre educação e museus, a busca por trabalhos sobre "cidade educadora" apresenta um número reduzido de estudos, e se apresenta ainda mais reduzido quando tentamos relacionar as palavras: "museu", "educação" e "cidade educadora". 
Tal constatação é curiosa, visto que, como já apresentado neste artigo, a definição de museu e cidade educadora é muito próxima, levando a crer que haveria uma maior produção de estudos sobre esta relação.

A dificuldade em definir o que é "cidade educadora" pode se configurar como um dos motivos para esse número reduzido de trabalhos, já que, conforme ressaltado anteriormente, este é um conceito aberto e não existe nenhum mecanismo ou órgão responsável pelo acompanhamento dos objetivos e missão propostos pela Carta da Cidade Educadora. Cabe ainda destacar que inúmeras cidades, que não fazem parte da Associação Internacional das Cidades Educadoras, tal como Taubaté, apresentam diretrizes pelas quais as cidades educadoras pregam e aplicam em seu território, embora se desconheça o resultado de algumas das ações desenvolvidas.

Em relação à literatura sobre museus e educação não formal, é possível perceber que ainda há uma dependência ou forte ligação com a educação formal e são poucas as iniciativas que tentam fazer com que o museu amplie seu olhar, conectando-se cada vez mais com o espaço em que se encontra.

No entanto, em estudo exploratório, já é possível afirmar que o Museu Monteiro Lobato/Sítio do Pica Pau Amarelo, espaço de investigação da pesquisa a ser desenvolvida, apresenta-se como possibilidade de ultrapassar o espaço escolar. As visitas são guiadas pelos personagens criados por Monteiro Lobato (Narizinho, Emília, Pedrinho, entre outros) que conduzem os grupos pela casa contando histórias. Em seguida é apresentada uma peça teatral baseada em alguma história do autor, com os personagens citados acima. No estudo exploratório foi também possível verificar que a maioria das crianças retorna com seus familiares, o que pode significar que o equipamento cultural está conseguindo despertar o interessa desses visitantes.

Em suma, por mais que as pesquisas tenham avançado - e já faz tempo que o campo museal aponta que a educação não deve estar centrada apenas na escola - , compreendemos que falta uma literatura concernente ao aproveitamento do potencial educativo do território.

\section{Notas}

1 Nomenclatura a ser utilizada ao longo do artigo.

2 IBGE. Retrieved from http://cidades.ibge.gov.br/xtras/perfil.php?codmun=355410.

3 Lei n ${ }^{\circ} 12.388$ (2011). Confere ao Município de Taubaté, no Estado de São Paulo, o título de Capital Nacional da Literatura Infantil. Diário Oficial da União. Col. 3 (03/03/11), 3. Retrieved from http://www.planalto.gov.br/ccivil_03/_Ato2011-2014/2011/Lei/ L12388.htm.

4 Assembleia Legislativa do Estado de São Paulo. (2011, 27 de Julho). Taubaté, a capital nacional da literatura infantil. Retrieved from https:/ / www.al.sp.gov.br/noticia/?id=285690. 
Decreto n 33.909 (1958). Dispõe sôbre instalações de Museus Históricos e Pedagógicos em cidades que especifica Diretoria Geral da Secretaria de Estado dos Negócios do Governo (04/11/58), s/p. Retrieved from http://www.al.sp.gov.br/repositorio/legislacao/ decreto/1958/decreto-33909-04.11.1958.html.

6 Processo iniciado em 1969 pelo SPHAN (Serviço do Patrimônio Histórico e Artístico Nacional) e concluído pelo CONDEPHAAT (Conselho de Defesa do Patrimônio Histórico, Arqueológico, Artístico e Turístico do Estado de São Paulo). Ou seja, de 1958 a 1969, o casarão ficou fechado, em ruínas.

Apesar de no Guia Brasileiro de Museus (Ibram, 2011) não estar descrita a tipologia "literatura", o Cadastro Nacional de Museus apresenta uma lista dos museus que têm atividades ligadas à memória da literatura, estando presente o Museu Histórico, Folclórico e Pedagógico Monteiro Lobato. Retrieved from http://www.museus.gov.br/wp-content/uploads/2011/07/museuliteratura1.pdf. Nos documentos oficiais da prefeitura o museu é assim caracterizado.

9 International Association of Educating Cities. Retrieved from http://www.edcities.org/en/.

10 Trilha Cultural - Museus de Taubaté. (2014, 30 de Novembro). SISEM-SP e ACAM Portinari lançam o projeto "Trilha Cultural" em Taubaté [Web log post]. Retrieved from https:/ / trilhaculturalmuseusdetaubate.wordpress.com.

11 Museu Monteiro Lobato. (2016, Setembro). Retrieved from http:/ / museumonteirolobato.com.br/setembro-2016.

12 Lei nº11904/09 (2009). Institui o Estatuto de Museus e dá outras providências. Diário Oficial da União (20/11/09), p. 1. Retrieved from http://www.planalto.gov.br/ccivil_03/ _Ato2007-2010/2009/Lei/ L11904.htm\%20Acesso:\%20novembro/2017.

13 Manual de Consulta do Projeto Educar 2009/11. (s/d). Vale do Paraíba Paulista História, desenvolvimento, folclore (Vol.1), p. 99. Retrieved from http://www.gazetavaleparaibana.com/volume1.pdf.

14 Je vais au plus simple, car il n'y a pas de modèles et il y a au contraire une grande diversité d'applications du concept. Je préfère donc dire: Le musée "normal" est un bâtiment, une collection, des publics/L'écomusée est um territoire, des patrimoines, une communauté. Le musée normal, c'est de la culture "hors-sol". L'écomusée, c'est un musée enraciné dans la culture vivante des habitants. Il faut aussi définir les objectifs. Pour moi, l'écomusée fait partie des instruments de la dimension culturelle du développement local. Les musées ordinaires ont plutôt comme objectifs le développement de la culture, la conservation du patrimoine, l'accueil de touristes, la formation des écoliers, etc.

15 Apesar de no Guia Brasileiro de Museus de 2013 não estar descrita a tipologia "literatura", o Cadastro Nacional de Museus (2011) apresenta uma lista dos museus que têm atividades ligadas à memória da literatura, estando presente o Museu Histórico, Folclórico e Pedagógico Monteiro Lobato. Retrieved from http://www.museus.gov.br/wp-content/uploads/2011/07/museuliteratura1.pdf.

Os autores do texto escrevem segundo o novo acordo ortográfico. 


\section{Referências}

Arroyo, M. G. (2010). Políticas educacionais e desigualdades: À procura de novos significados. Educação E Sociedade, 31(113), 1381-1416. doi: 10.1590/S0101-73302010000400017

Bauman, Z. (2013). Espaço público. In E. Bosh (Ed.), Educação e vida urbana. 20 anos de cidades educadoras (pp. 51-62). Torres Novas, Portugal: Almondina.

Cabral, M. (2012). Educação patrimonial x educação museal. In A. B. Tolentino (Org.), Educação patrimonial: Reflexões e práticas (pp. 38-43). João Pessoa: Superintendência do IPHAN na Paraíba.

Cadastro Nacional de Museus (2011). Os museus e a memória da literatura brasileira. Retrieved from http://www.museus.gov.br/wp-content/uploads/2011/07/museuliteratura1.pdf

Canclini, N. G. (2013). Comunicações, conhecimento e cidade: Um debate intercultural. In E. Bosh (Ed.), Educação e vida urbana. 20 anos de cidades educadoras (pp. 155-164). Torres Novas, Portugal: Almondina.

Carta das Cidades Educadoras. (2004). Gênova: Associação Internacional de Cidades Educadoras. Retrieved from http://www.edcities.org/wp-content/uploads/2013/10/Carta-Portugues.pdf

Carvalho, M. C. (2016). Tecnologia e cognição em espaços de educação não formal: A cidade educadora. In R. I. Bannel, et al. (Eds.), Educação no século XXI - Cognição, tecnologias e aprendizagens (pp. 77-156). Rio de Janeiro: Ed. Vozes.

Carvalho, M. P. (2014). Educação patrimonial: Uma experiência com alunos e professores no município de Vila Velha/ES (Dissertação de mestrado). Instituto Federal de Educação, Ciência e Tecnologia do Espírito Santo, Vitória, Brasil.

Chagas, M. S. (2009). A imaginação museal: Museu, memória e poder em Gustavo Barroso, Gilberto Freyre e Darcy Ribeiro. Rio de Janeiro: MinC/Ibram.

Cury, P. G., \& Moraes, F. B. (2012). Patrimônio + educação: Possibilidades e perspectivas em suas novas configurações. CATS 2012 - Congresso de Arquitetura, Turismo e Sustentabilidade. Retrieved from http://www.catscataguases.com.br/dvd_2012/comunicacao_eixo3.html

Dourado, L. F., \& Oliveira, J. F. (2009). A qualidade da educação: Perspectivas e desafios. Cad. Cedes, 29(78), 201-215. Retrieved from http:/ / www.scielo.br/pdf/ccedes/v29n78/v29n78a04.pdf

Expomus. (2010). Plano museológico: Museu Histórico, Folclórico, Pedagógico Monteiro Lobato. Expomus e Secretaria de Estado da Cultura de São Paulo: ACAM Portinari.

Franco, F. C., Prados, R. M. N., \& Bonini, L. M. (2015). Cultura, cidadania e patrimônio cultural: Interfaces entre a escola, a cidade e as políticas culturais na cidade de Guararema. PERSPECTIVA, 33(1), 319-344. Retrieved from https:/ periodicos.ufsc.br/ index.php/perspectiva/article/view/2175-795X.2014v33n1p319

Gomes, M. V. S. (2013). Para além dos muros da escola: Caminhos para compreensão da educação na cidade (Dissertação de mestrado). Universidade Federal do Rio de Janeiro, Rio de Janeiro, Brasil. 
Guarda. (2017). VII Congresso Nacional da Rede Territorial Portuguesa das Cidades Educadoras - IDENTICIDADES, Portugal.

Ibram. (2011). Guia dos museus brasileiros. Brasília: Instituto Brasileiro de Museus.

Lopes, J. T. (2008). Da democratização à democracia cultural: Uma reflexão sobre políticas culturais e espaço público. Portugal: Profedições.

Martin, C. (2014). Cidades educadoras no Estado de São Paulo: Análise das ações frente ao perfil temático e aos princípios do movimento (Dissertação de mestrado). Universidade Metodista de Piracicaba, Piracicaba, Brasil.

Melo, M. D. (2015). Educação museal: Reflexão sobre semelhanças e contrastes com uma forma escolar (Dissertação de mestrado). Universidade Federal de Pernambuco, Recife, Brasil.

Meneses, U. T. B. (2003). O museu de cidade e a consciência de cidade. In A. C. M. Santos, C. G. Kessel, \& C. Guimaraes (Orgs.), Museus \& cidades: livro do Seminário Internacional (pp. 255-282). Rio de Janeiro: Museu Histórico Nacional.

Moll, J. (2013). A cidade e seus caminhos educativos: escola, rua e itinerários juvenis. In E. Bosh (Ed.), Educação e vida urbana. 20 anos de cidades educadoras (pp. 213-224). Torres Novas, Portugal: Almondina.

Rémy, J., \& Voyé, L. (1992). A cidade: Rumo a uma nova definição?. Lisboa: Afrontamento.

Rodriguez, M. C. (2015). Materialidade e imaterialidade na transformação de residências particulares em patrimônio cultural: Hilda Hilst e a Casa Do Sol (Dissertação de mestrado). Universidade Federal de São Paulo, Escola de Filosofia, Letras e Ciências Humanas, Guarulhos, Brasil.

Sander, R. (2006). O museu na perspectiva da educação não formal e as tendências políticas para o campo da museologia (Dissertação de mestrado). Universidade de Passo Fundo-RS, Passo Fundo, Brasil.

Seibel-Machado, M. I. (2009). O papel do setor educativo nos museus: Análise da literatura (1987 a 2006) e a experiência do Museu da Vida (Tese de doutoramento). Instituto de Geociências da UNICAMP, Campinas, Brasil.

Silva, A. D. H. (2013). A educação em museus sob o olhar do Comitê de Educação e Ação Cultural (CECA-Brasil) (Dissertação de mestrado). Universidade Federal do Estado do Rio de Janeiro, Rio de Janeiro, Brasil.

Silva, C. F. (2013). Do NOPH ao Ecomuseu de Santa Cruz: Representações no jornal NOPH (1983-1990) e no jornal O Quarteirão (1993-2000) (Dissertação de mestrado).

Universidade Federal do Rio Grande do Sul, Porto Alegre, Brasil.

Trilla, J., et al. (Orgs.) (2008). Educação formal e não formal: Pontos e contrapontos. São Paulo: Summus.

Varine, H. (2006). L'ECOMUSEE un mot, deux concepts, mille pratiques. Retrieved from http://www.hugues-devarine.eu/img/cms/2006\%20Ecomus\%C3\%A9e,.pdf

Vianna, C. M. S. V. (2015). Professores de educação de jovens e adultos e museus: Percepções, usos e desusos (Dissertação de mestrado). Universidade do Estado do Rio de Janeiro, Rio de Janeiro, Brasil.

Vieira, E., \& Aquino, J. G. (2015). Sobre a pedagogização da experiência urbana: O projeto da cidade educadora. Revista Educação Unisinos, 19(3). Retrieved from http://revistas.unisinos.br/index.php/educacao/article/view/edu.2015.193.02 
Cristina Carvalho. Doutora em Educação pela Pontifícia Universidade Católica (PUC-Rio), Professora do Programa de Pós-Graduação em Educação-PUC-Rio, Vice Decana de Graduação do CTCH e Coordenadora do Grupo de Pesquisa em Educação, Museu, Cultura e Infância (GEPEMCI).

João Teixeira Lopes. Doutor em Sociologia da Cultura e da Educação pela Faculdade de Letras da Universidade do Porto (FLUP), Professor catedrático e Diretor do Departamento de Sociologia da Universidade do Porto (FLUP) e Presidente da Associação Portuguesa de Sociologia.

Clarisse Duarte Magalhães Cancela. Mestre em Educação - Universidade Federal do Estado do Rio de Janeiro (UNIRIO). Doutoranda em Educação Pontifícia Universidade Católica (PUC-Rio) e integrante do Grupo de Pesquisa em Educação, Museu, Cultura e Infância (GEPEMCI).

Data de submissão: 17/07/2017 | Data de aceitação: 29/09/2017

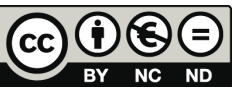

